\title{
Questionando textos multimodais: produção e uso de material didático para leitura crítica nas aulas de inglês
}

\author{
Carla Cristina de Souza \\ PUC-Rio / IFRJ
}

\begin{abstract}
Resumo
Buscando promover a leitura crítica de textos multimodais nas aulas de inglês, analiso dois anúncios destacando as escolhas para interação leitortexto e para a representação dos atores sociais no visual e no verbal. A partir das análises, apresento atividades que podem servir como exemplos de como questionar textos multimodais.

Palavras chave: elaboração de atividades, representação dos atores sociais, leitura crítica de gênero multimodal.
\end{abstract}

\begin{abstract}
Aiming to foster the critical reading of multimodal texts in English classes, this paper analyzes two advertisements highlighting the choices for the reader-text interaction and for the representation of social actors. Following this, activities based on the analysis are shown as examples of how to question multimodal texts.

Keywords: material design, representation of social actors, critical reading of a multimodal genre.
\end{abstract}

\section{INTRODUÇÃO}

No processo de ensino de leitura e produção de textos nas aulas de línguas, a diversidade cultural e os recursos semióticos diferentes da linguagem escrita são comumente deixados de lado, ignorando ou minimizando a importância desses elementos e a reflexão crítica sobre o uso de todos os modos semióticos. É imprescindível que a escola propicie o questionamento desses gêneros compostos por múltiplas semioses e os temas por eles difundidos nos meios de comunicação, contribuindo para a formação de cidadãos críticos e reflexivos.

Entretanto, observa-se a dificuldade dos professores em lidar com textos multimodais de forma que as aulas contemplem a leitura crítica e a integração de escrita e imagem na produção de sentidos (OLIVEIRA, 2006; ALMEIDA, 2008 e 2011). Um dos motivos dessa dificuldade é o fato de que o conhecimento implícito que normalmente as pessoas têm sobre a multimodalidade não é suficiente para que elas 
leiam textos criticamente (NASCIMENTO et al., 2011). Assim como Lima (2009), acredito que primeiramente os professores devem desenvolver seu conhecimento linguístico-discursivo, e aqui incluo o que se refere à multimodalidade, a começar pela “compreensão acerca do papel das imagens enquanto textos (e não aportes ilustrativos) dotados de uma estrutura sintática própria e de conteúdo ideológico” (ALMEIDA, 2011, p. 60).

Visando trazer uma contribuição para o ensino de Inglês, proponho-me a analisar um exemplo de gênero multimodal: o anúncio publicitário. Os anúncios publicitários utilizam as linguagens verbal e visual para envolver o leitor. Contudo, neste gênero, a tentativa de convencimento se torna ainda mais evidente, já que nele são utilizadas estratégias específicas de persuasão através da disseminação de aspectos ideológicos que ao mesmo tempo refletem e produzem a nossa sociedade (PEREZ, 2004, p. 106). O uso de anúncios em sala de aula pode contribuir para o entendimento de como esses textos são construídos para influenciar seus leitores e conscientizar os alunos sobre como as peças publicitárias podem manipular e moldar o comportamento das pessoas, preparando-os para avaliar melhor o que está sendo oferecido, com um olhar mais crítico. Assim, os objetivos deste trabalho são 1) analisar os textos usando ferramentais teóricos oferecidos pela “Gramática do Design Visual” de Kress \& van Leeuwen e as categorias para o exame da representação dos atores sociais no discurso (VAN LEEUWEN,1997 e 2008), ambos desenvolvidos a partir da Linguística SistêmicoFuncional; e 2) apresentar atividades para exemplificar meios de explorar os textos criticamente nas aulas de inglês a partir das análises.

Para tanto, primeiramente, apresento o referencial teórico e as categorias para a análise. A seguir, descrevo brevemente o gênero e a metodologia, para então voltar-me ao exame dos textos e a discussão dos resultados, com possíveis interpretações. Finalmente, apresento exemplos de atividades, seguidas das considerações finais da pesquisa. Passemos, então, à arquitetura teórica.

\section{A GRAMÁTICA DO DESIGN VISUAL E A REPRESENTAÇÃO DOS ATORES SOCIAIS}

Além da linguagem verbal, outros modos semióticos escolhidos para integrar o evento discursivo transmitem significados aos leitores. Então, para entender as mensagens veiculadas, é necessário estudar a multimodalidade, ou seja, a integração de 
modos de comunicação distintos como os sons, as imagens, a escrita, os gestos, etc. Neste trabalho, busco examinar anúncios retirados de revistas e, por conseguinte, minha análise ficará restrita às imagens e à escrita e sua diagramação. Para tanto, baseei-me na Teoria da Multimodalidade proposta por Kress \& van Leeuwen, que investigaram as escolhas imagéticas na cultura ocidental e desenvolveram categorias para seu estudo. $\mathrm{O}$ quadro 1 mostra resumidamente as categorias que serão utilizadas neste artigo e ao que elas se referem, mas elas serão retomadas e devidamente exemplificadas nas análises.

Quadro 1 - Metafunções na imagem (Adaptado de KRESS e VAN LEEUWEN, 2006)

\begin{tabular}{|c|c|c|}
\hline Representacional & \multicolumn{2}{|c|}{$\begin{array}{l}\text { Estrutura narrativa - Representa participantes enquanto envolvidos em ações e } \\
\text { acontecimentos } \\
\text { Estrutura conceitual - Descreve o participante através de seus atributos físicos e/ou } \\
\text { psicológicos }\end{array}$} \\
\hline \multirow{4}{*}{$\begin{array}{l}\text { Interativa } \\
\text { Descreve o tipo de } \\
\text { relação construída } \\
\text { entre participante } \\
\text { representado e } 0 \\
\text { leitor }\end{array}$} & \multicolumn{2}{|c|}{$\begin{array}{l}\text { Contato } \\
\text { Direção do olhar do } \\
\text { participante } \\
\text { representado }\end{array} \quad \begin{array}{l}\text { Demanda - olhar do participante representado virado } \\
\text { direto para o leitor } \\
\text { oferta - olhar do participante representado para outra } \\
\text { direção }\end{array}$} \\
\hline & \multicolumn{2}{|c|}{$\begin{array}{l}\text { Distância social Relação entre o tamanho do objeto registrado e a impressão de } \\
\text { distância ou proximidade dessa imagem para o leitor dependendo do corte da imagem }\end{array}$} \\
\hline & Atitude & $\begin{array}{l}\text { Ângulo do corpo do personagem representado } \\
\text { Ângulo frontal - maior envolvimento } \\
\text { Ângulo obliquo - distanciamento } \\
\quad \text { Quando o participante representado é visto de: } \\
\text { Ângulo superior - participante interativo está na posição de poder } \\
\text { Mesmo ângulo- participante interativo e representado tem igualdade de } \\
\text { poder } \\
\text { Ângulo inferior - participante interativo está em posição de } \\
\text { inferioridade }\end{array}$ \\
\hline & Modalidade & $\begin{array}{l}\text { Uso de recursos para modificar cores (como saturação, diferenciação e } \\
\text { modulação) contextualização (ausência de cenário até o cenário cheio } \\
\text { de detalhes); iluminação; brilho, atenção ou não a detalhes e } \\
\text { caracterização de profundidade }\end{array}$ \\
\hline Composicional & \multicolumn{2}{|c|}{$\begin{array}{l}\text { Valor informativo: } \\
\text { Ideal (superior da imagem - idealizações, apelo emocional) X Real (parte inferior - } \\
\text { cotidiano, prática, mais precisão) } \\
\text { Dado (à esquerda - o leitor já sabe, algo familiar, esperado) X Novo (à direita - o que é } \\
\text { desejado ou no que leitor deve prestar atenção) } \\
\text { Centro (núcleo da informação)X Margens (elementos subservientes) }\end{array}$} \\
\hline & \multicolumn{2}{|c|}{$\begin{array}{l}\text { Saliência: Estratégias para dar maior ou menor destaque a certos elementos no texto } \\
\text { visual (Tamanho relativo dos elementos, coordenação entre as cores utilizadas, } \\
\text { posicionamento desses itens em primeiro ou segundo plano) }\end{array}$} \\
\hline & \multicolumn{2}{|c|}{$\begin{array}{l}\text { Enquadramento: os elementos da imagem podem se mostrar como interligados ou } \\
\text { desconectados (por linhas divisórias implícitas ou explicitas, por exemplo) }\end{array}$} \\
\hline
\end{tabular}


Assim, a gramática do design visual de Kress \& Van Leeuwen (2006) presta-se a atender a necessidade de fornecer os instrumentos para a análise das imagens e discussão de seus possíveis significados. Essa proposta segue a perspectiva hallidayana, mas nomeia as três metafunções de forma diferente: as metafunções Textual, Ideacional e Interpessoal são chamadas de Composicional, Representacional e Interativa respectivamente. Portanto, podemos identificar nas imagens a relação entre o que é visto e quem observa (função interativa); como a natureza dos eventos, objetos e participantes envolvidos e as circunstâncias em que ocorrem são construídas (metafunção representacional); e observar recursos para (dis)conectar os elementos e distribuir a informação na imagem, atribuindo a eles maior ou menor ênfase e valor (Unsworth, 2001).

Além das categorias descritas no quadro 1, chamo a atenção para as formas que os atores sociais são representados, que podem trazer à tona posicionamentos ideológicos em relação a eles e suas atividades (RESENDE \& RAMALHO, 2006), aspecto de grande importância na discussão crítica de textos. Para examinar as diferentes escolhas representacionais, utilizei a descrição sociosemântica de van Leeuwen (1997, 2008). Por não ser possível abarcar todas as categorias neste trabalho, concentro-me apenas em algumas das mais proeminentes nos textos examinados, que apresento no esquema organizado no quadro 2. Essas categorias partem da metafunção ideacional e por meio delas é possível mostrar como as realizações linguísticas e imagéticas podem revelar a visão de mundo veiculada pelo texto.

Segundo van Leeuwen $(1997,2008)$, as características mais gerais para a representação dos atores sociais são a exclusão e a inclusão de indivíduos ou grupos sociais. Se incluídos, eles podem ser mostrados como agentes ou pacientes de ações condenadas ou aprovadas segundo convenções sociais e morais. Pode-se também expor as pessoas de forma genérica ou específica. A representação é genérica quando pessoas são vistas como um grupo indistinto, representado por categorização cultural (roupa, acessórios e objetos) ou biológica (tipos físicos padronizados) que podem imprimir estereótipos que agregam valores positivos ou negativos a certos grupos socioculturais. Concluindo sua categorização de recursos visuais que realizam significados experienciais, van Leeuwen (2008) define a escolha entre a representação individual ou grupal, sendo que essa última pode ser feita de duas formas. Pode-se destacar um dos participantes representados, dando a ele maior importância, o que se constitui em uma diferenciação ou caracterizar um grupo como uma massa de pessoas cujas 
características individuais são apagadas por homogeneização. O quadro 2, elaborado com base em van Leeuwen, 1997 e 2008, resume as categorias usadas para a representação visual dos atores sociais:

Quadro 2 - Categorias para a Representação dos Atores Sociais

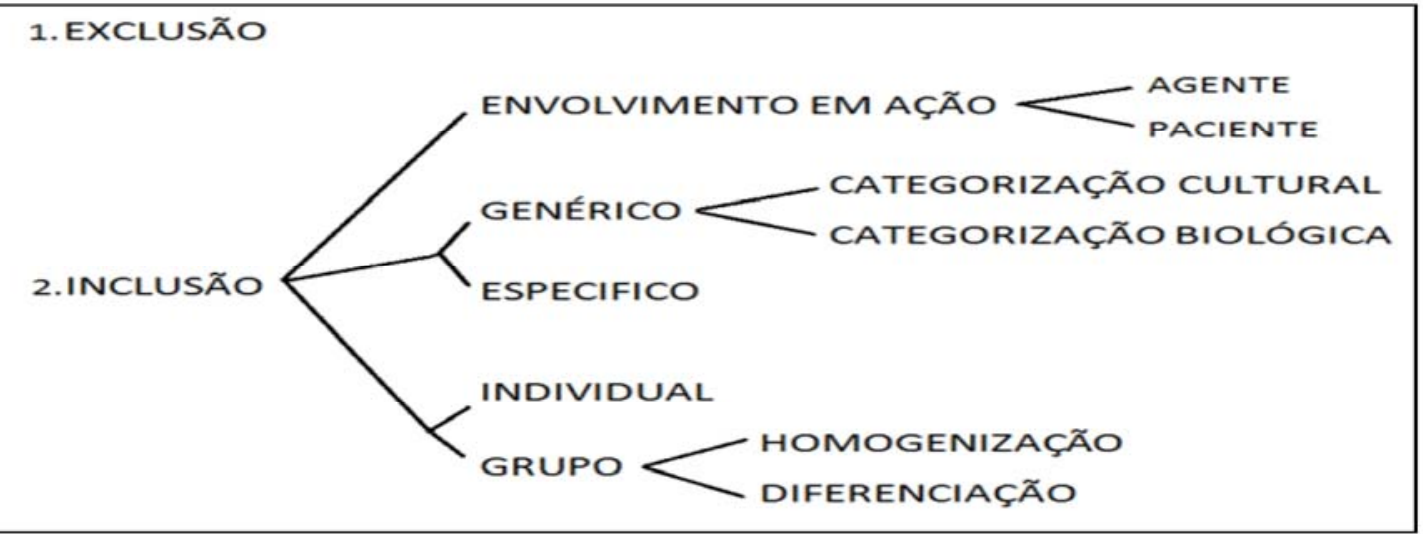

\section{ANÚNCIOS PUBLICITÁRIOS: O GÊNERO E A ANÁlise DOS TEXTOS SELECIONADOS}

Saliento aqui a importância de ensinar a ler textos criticamente tomando como base a noção de gênero, a fim de relacionar o evento comunicativo ao contexto em que ele ocorre. Mesmo sabendo das limitações e da inevitável incompletude no ensino explícito de gêneros em sala de aula (DEVITT, 2009), é essencial que os professores o façam da melhor forma possível. Assim, nós professores podemos a conscientização de que os gêneros são conteúdos sociais, representações nem sempre explícitas de ideologias. Essa visão é corroborada por Ramos (2004, p. 116), que advoga que gêneros textuais podem ser usados como "um recurso pedagógico poderoso" já que proporcionam a possibilidade de analisar as características dos discursos com que os alunos têm que lidar e dão suporte ao professor na construção de aulas socialmente relevantes.

Adoto como ponto de partida o conceito de gêneros discursivos de Martin (1997), que os define como sistemas estruturados em estágios, organizados, selecionados e postos em prática como meios para alcançar propósitos específicos. Nas análises, devido ao escopo deste artigo, tenho como foco o exame dos contextos cultural e situacional e das escolhas linguísticas e visuais materializadas através deles. Desta 
forma, busquei levantar dados sobre a atividade social desenvolvida, seus propósitos comunicativos, a relação entre os participantes da interação e seus papéis no evento comunicativo e o papel das linguagens verbal e visual, bem como o modo como elas são usadas nos anúncios.

Os anúncios publicitários são veiculados em jornais, revistas e outros meios de comunicação com os propósitos de vender produtos e ideias; criar uma imagem, divulgar e promover a marca e informar o consumidor; mudar hábitos; recuperar uma economia e promover o consumo; e criar, expandir, corrigir, educar, consolidar e fazer a manutenção do mercado (SAMPAIO, 2003). Produzir esses textos requer muita arte e ciência e eles podem ser uma arma muito poderosa para persuasão.

Citelli (2004) cita alguns dos recursos de persuasão comumente usados em anúncios publicitários para o alcance dos propósitos nesse gênero, dos quais destaco a criação de inimigos (o produto é mostrado como forma de combater ou se livrar de algo indesejável, tornando-se a solução para um problema), o uso de estereótipos (uso de "verdades consagradas” que dificultam questionamentos sobre a mensagem veiculada), a afirmação (convencimento do leitor por expressões de certeza), a repetição (que aumenta a possibilidade de concordância pela constância reiterativa, bem como cumpre o papel de estratégia de memorização) e o apelo à autoridade (validação do que é dito/mostrado pela fala ou imagem de especialistas, pesquisas, celebridades, etc., aumentando o Engajamento), encontrados nos textos analisados.

Através de construções ideológicas persuasivas usando o verbal e o visual, os textos publicitários criam novas percepções da realidade e conseguem seduzir consumidores em potencial, que são os participantes para os quais o texto é meticulosamente criado. Anunciantes, pessoas ligadas aos veículos onde o anuncio será veiculado e agências (empresas especializadas na técnica e na arte da propaganda e que reúnam tecnologias específicas e corpo de profissionais de diversas especializações) são os outros participantes desse gênero, que estão envolvidos na elaboração cuidadosa, aperfeiçoamento e divulgação dos anúncios. Para atingir seus objetivos, usam-se imagens e texto escrito, sendo este último também representado visualmente. O uso dessas semioses é estrategicamente planejado e elas são “entrelaçadas” na construção do texto para convencer e seduzir o público-alvo (DUARTE, 2011).

Segundo Sampaio (2003), todos os elementos do anúncio são construídos para agir sobre os centros sensoriais, emocionais e lógicos do consumidor, atendendo aos princípios básicos de criatividade, emoção e interesse, pertinência e compreensão. 
Para isso, ela deve ser rápida (e conquistar a atenção de imediato, com título e imagem que despertem o interesse no anúncio impresso), eficiente (facilmente compreendida) e eficaz (capaz de motivar o leitor a mudar de atitude e agir, adquirindo o que está sendo anunciado). Passemos, agora, ao exame dos textos.

Para o exame do gênero anúncio publicitário, escolhi exemplares que foram retirados de revistas, sendo um deles produzido para o público-alvo feminino e o outro para o masculino. Com essa seleção fica claro um dos objetivos principais da propaganda, que é conquistar seu consumidor. Por isso, a mudança do público alvo implica em formas diversas de construir o anúncio. Além disso, há produtos que são anunciados apenas nas revistas femininas e outros apenas nas masculinas.

Para facilitar a visualização do que está escrito, transcrevo o texto em caixas próximas a ele na figura 1. A análise das imagens, mostrada no quadro 3 logo após a figura, destaca as funções Interativa, Representacional e Composicional com base na Gramática do Design Visual de Kress e van Leeuwen. No quadro 3 examino brevemente como é feita a Representação dos Atores Sociais e apresento a seguir a interpretação e discussão das escolhas verbais e visuais.

Figura 1 - Anúncio 1. Fonte: Marie Claire, 2011

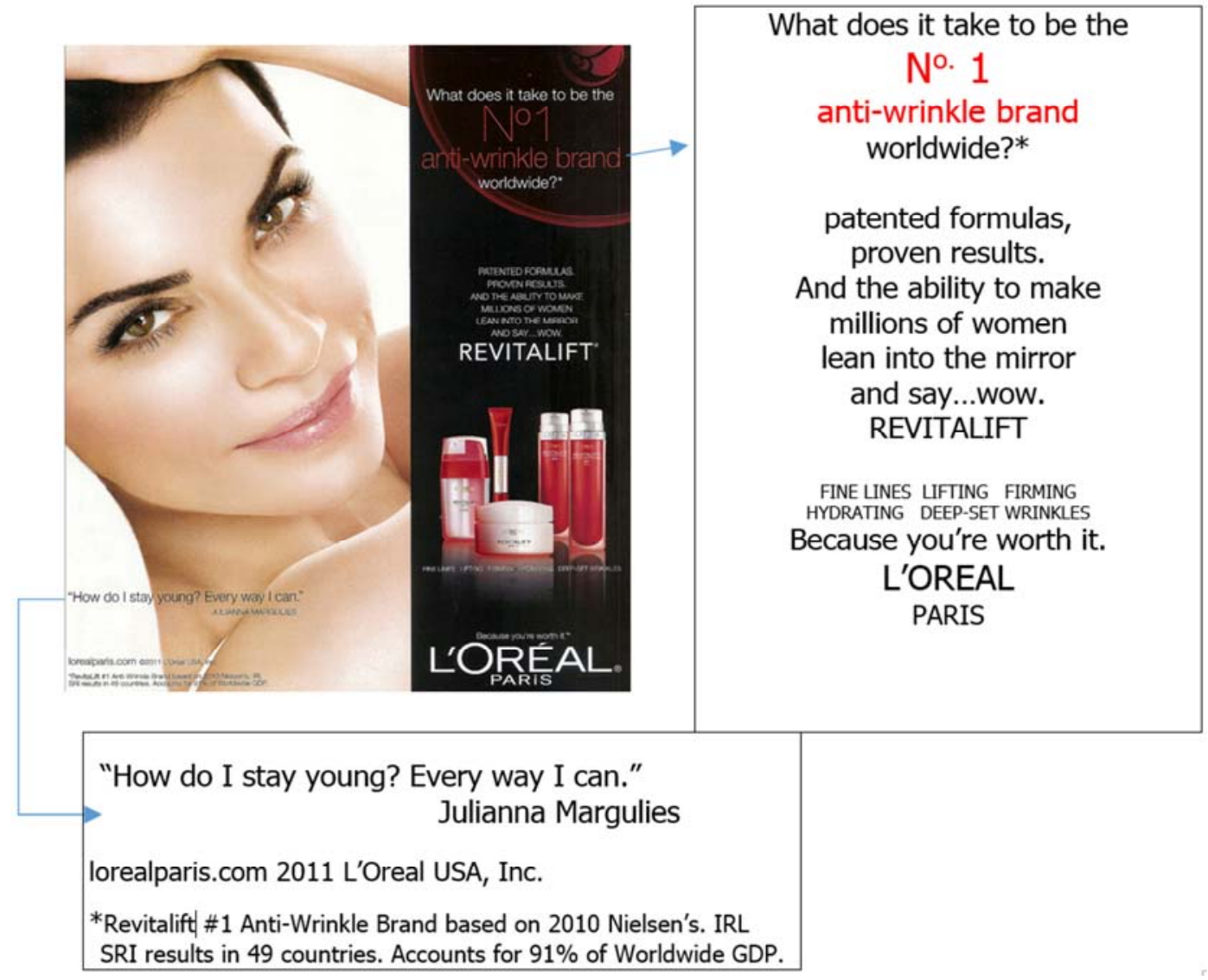


Quadro 3 - Análise da imagem no anúncio 1.

\begin{tabular}{|c|c|c|c|}
\hline \multirow{3}{*}{\multicolumn{2}{|c|}{$\begin{array}{l}\mathrm{M} \\
\mathrm{E} \\
\mathrm{T} \\
\mathrm{A} \\
\mathrm{F} \\
\mathrm{U} \\
\mathrm{N} \\
\mathrm{C} \\
\AA \\
\mathrm{A} \\
0\end{array}$}} & SALIÊNCIA & $\begin{array}{l}\text { Na parte direita do anúncio dentro da faixa preta na vertical: Foco no } \\
\text { hidratante e na marca. Os produtos são mostrados como se iluminados } \\
\text { por refletores, destacando-0s. } 0 \text { fundo escuro (que contrasta com essa } \\
\text { iluminação) e o uso das cores dos produtos e na linguagem verbal dão } \\
\text { ainda maior proeminência a eles. }\end{array}$ \\
\hline & & MOLDURA & $\begin{array}{l}\text { Nome da linha de produtos está no meio da faixa preta em letras } \\
\text { bastão brancas, emoldurado pelas outras informaçốes (incluindo a foto } \\
\text { dos produtos) e pelo preto }\end{array}$ \\
\hline & & $\begin{array}{l}\text { VALOR } \\
\text { INFORMACIONAL }\end{array}$ & $\begin{array}{l}\text { Considerando anúncio inteiro: Julianna Margulies é o dado e o produto } \\
\text { e suas informaçoos são o novo } \\
\text { Considerando a faixa preta: Nome da linha de produtos, suas } \\
\text { características e foto no centro. Na parte superior ( } 0 \text { ideal), informação } \\
\text { de que é a marca número } 1 \text { em anti-rugas e na inferior (real) a marca } \\
\text { L'OREAL PARIS. }\end{array}$ \\
\hline $\begin{array}{l}\text { M } \\
\text { E } \\
\text { T } \\
\text { A }\end{array}$ & $\begin{array}{l}R \\
E \\
P \\
R \\
E \\
S \\
E\end{array}$ & \multicolumn{2}{|c|}{$\begin{array}{l}\text { REPRESENTAÇÕES CONCEITUAIS - foco à esquerda nos atributos e identidade da } \\
\text { participante e à direita na linha de produtos. } \\
\text { Vetor formado pelo nariz da atriz como se apontando para os produtos. }\end{array}$} \\
\hline $\begin{array}{l}\mathrm{F} \\
\mathrm{U} \\
\mathrm{N} \\
\mathrm{C} \\
\AA \\
\mathrm{A} \\
0\end{array}$ & $\begin{array}{l}\text { N } \\
\text { A } \\
\text { C } \\
\text { I } \\
0 \\
\text { N } \\
\text { A } \\
\text { L }\end{array}$ & \multicolumn{2}{|c|}{$\begin{array}{l}\text { REPRESENTAÇÃO DOS ATORES SOCIAIS } \\
\text { Mulher representada como paciente } \\
\text { Foco na pele da mulher }\end{array}$} \\
\hline & CONTATO & Demanda - Olhar direto para o leitor \\
\hline & & $\begin{array}{l}\text { DISTÂNCIA } \\
\text { SOCIAL } \\
\end{array}$ & Pessoal - Próximo (Close Shot) \\
\hline & & ATITUDE & $\begin{array}{l}\text { Ângulo - Igualdade de poder observador/ observado } \\
\text { Participante observado (atriz Julianna Margulies) com corpo em direção } \\
\text { diferente da cabeça, sendo somente esta virada na direção da } \\
\text { leitora/observadora }\end{array}$ \\
\hline & & MODALIDADE & $\begin{array}{l}\text { Cor vermelha, tipo e tamanho das letras em " } N 1 \text { anti-wrinkle brand", } \\
\text { destacando esta parte do texto. } \\
\text { Na foto, ausência de fundo e brilho da pele. }\end{array}$ \\
\hline
\end{tabular}

Em primeiro lugar, podemos perceber que a imagem está dividida em duas partes no eixo horizontal e, nesta composição, o produto é mostrado à direita. À esquerda vemos a foto de uma mulher, Julianna Margulies, que é uma atriz famosa, principalmente pelo papel principal na série The good wife. Ela representa o dado, o que já é conhecido pelo leitor. Já do lado direito, destaca-se o produto e informações sobre 
ele, apresentado como novidade, o que se deve usar para conseguir o mesmo efeito visto no rosto da mulher à esquerda (pele linda e radiante).

A atriz é representada conceitualmente na foto, visto que o foco da imagem é a pele da mulher, como se ela fosse um objeto a ser analisado. Além disso, não há pano de fundo e o foco é completamente direcionado para a participante e seus atributos. Julianna Margulies é vista como uma celebridade que é consumidora do produto e que o endossa. Essa é uma das estratégias mencionadas por Citelli (2004, p. 59 e 60), denominada "apelo à autoridade": uma figura reconhecida traz credibilidade ao que está sendo oferecido.

Assim, o anúncio passa a impressão de que a mulher comum, leitora da revista, pode usar os mesmos produtos de beleza que “as famosas”, conquistando, assim, os mesmos atributos (Neste caso, um estereótipo de beleza, a busca pela pele jovem e perfeita, sem rugas ou manchas, muito valorizados em nossa sociedade). Essa leitura é ainda mais facilitada pela forma como a personagem é representada, parecendo estar bem próxima à leitora.

Apesar da atriz ser representada com o corpo virado para o lado direito (o que pode ser interpretado como se ela "não fizesse parte do mesmo mundo" que a leitora), seu rosto está voltado para a observadora, olhando diretamente para ela (como se demandando uma resposta) e no mesmo ângulo (em posição de equidade), como uma pessoa íntima em uma conversa informal, uma "igual”. A noção de diálogo com a leitora é retomada nas palavras atribuídas à atriz que estão entre aspas logo abaixo de sua foto: "How do I stay young? Every way I can."

A frase da atriz também demanda uma resposta da leitora, mas é logo respondida. O modo interrogativo parece ter sido usado como prevendo a reação da leitora e uma possível dúvida que ela possa ter, mas, nesse caso, a pergunta é usada principalmente para engajar o interlocutor, como guiando-o para uma conclusão lógica. Assim, o uso da interrogativa é usado como estratégia para trazer o "leitor para conversa” e, já na frase seguinte, apresentar “a verdade” (o que o anuncio quer que o leitor acredite). Percebemos melhor essa estratégia na primeira frase da parte preta à direita. Apresentase a pergunta "What does it take to be the No 1 anti-wrinkle brand worldwide?", usada aqui como uma pergunta retórica que pretende simplesmente apresentar o produto como “o melhor”, dar ênfase à essa ideia e convencer a leitora. Ao lado do ponto de interrogação, há o asterisco, que remete a uma nota com estatísticas, representando pessoas como números (o que também é feito em "millions of women lean into the 
mirror and say...wow”), trazendo a ideia de consenso. Logo depois da pergunta na parte superior do anúncio, temos a resposta, que é mostrada também como fato incontestável: fórmulas patenteadas e os resultados comprovados fazem a linha de produtos da marca revitalift a melhor do mundo.

Apesar de trazer a voz de alguém para o texto, o objetivo não é o de considerar outras opiniões, mas sim se fazer valer de mais um argumento a favor do produto. Portanto, há contração dialógica com o uso da fala da atriz, como também nas outras partes do texto, que lançam proposições como verdades absolutas, sem nenhuma modalização ou chamada ao diálogo. Essas escolhas podem ser devido à tentativa de persuadir pela certeza, não deixando dúvidas, não proporcionando diferentes opções.

Cabe ressaltar ainda que o wow em "the ability to make millions of women lean into the mirror and say...wow" fortalece a concepção construída de que o produto funciona e tem um impacto positivo. Nesse mesmo trecho, podemos perceber que as mulheres são apassivadas. É o produto que as faz "se apoiar no espelho e dizer uau”. Portanto, elas sofrem a ação do Revitalift. Do mesmo modo, a única mulher vista na imagem, que foi apresentada como consumidora do produto, também não está envolvida em ação. Sua imagem está em um fundo totalmente branco, o que reforça a ideia de que ela é apenas um exemplo de ação do produto para o escrutínio do leitor.

Passemos, agora, para o exame do anúncio de um hidratante da marca L’oreal, para homens (figura 2).

Figura 2 - Anúncio 2. Fonte: Men’s Health, 2011.

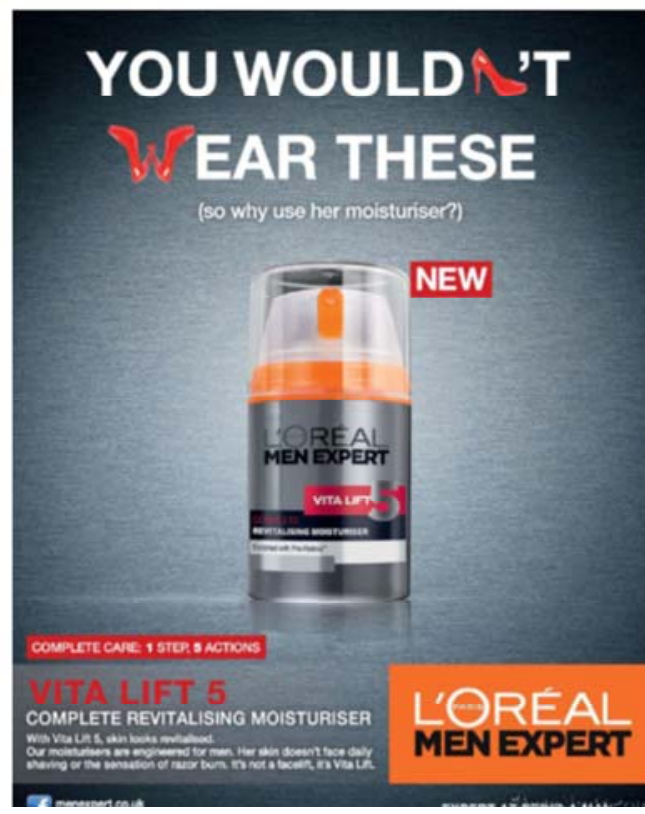

\section{YOU WOULDN'T \\ WEAR THESE}

(so why use her moisturiser?)

Complete care: 1 step, 5 actions

VITA LIFT 5

COMPLETE REVITILISING

MOISTURIZER

With vita lift 5 , skin looks revitilised

Our moisturisers are engineered for men.

Her skin doesn't face daily shaving or the sensation of razor burn. It's not a facelift, it's Vita Lift.

\section{L'OREAL} MEN EXPERT 
Quadro 4 - Análise da imagem no anúncio 2.

\begin{tabular}{|c|c|c|c|}
\hline \multirow{3}{*}{$\begin{array}{l}\text { M } \\
\mathrm{E} \\
\mathrm{T} \\
\mathrm{A} \\
\mathrm{F} \\
\mathrm{U} \\
\mathrm{N} \\
\mathrm{C} \\
\mathrm{D} \\
\mathrm{A} \\
0\end{array}$} & $\begin{array}{l}\text { C } \\
0 \\
M\end{array}$ & SALIÊNCIA & $\begin{array}{l}\text { Foco no hidratante, que parece irradiar uma luz. Cor do recipiente } \\
\text { usada no fundo de todo o anúncio. As cores laranja e vermelho } \\
\text { (também vistas no pote do produto) são usadas para destacar partes } \\
\text { importantes do texto }\end{array}$ \\
\hline & $\begin{array}{l}\text { p } \\
0 \\
\text { S }\end{array}$ & MOLDURA & $\begin{array}{l}0 \text { produto é envolto por uma luz branda, que } 0 \text { destaca do fundo } \\
\text { preto. }\end{array}$ \\
\hline & $\begin{array}{l}\text { I } \\
\text { C } \\
\text { I } \\
0 \\
\text { N } \\
\text { A } \\
\text { L }\end{array}$ & $\begin{array}{l}\text { VALOR } \\
\text { INFORMACIONAL }\end{array}$ & $\begin{array}{l}0 \text { produto está no centro, destacado por cores. Não há nada para } \\
\text { distrair a atenção do leitor (nenhuma outra pessoa ou objetos). Na } \\
\text { parte superior (o ideal), está a ideia de não haver necessidade de usar } \\
\text { produtos para mulheres. Nessa parte, que reflete } 0 \text { que se deseja } \\
\text { alcançar, também se destaca a palavra new (novo). Já na parte } \\
\text { inferior, estão as informações sobre o produto de forma bem direta e a } \\
\text { marca L'OREAL PARIS. }\end{array}$ \\
\hline M & $\begin{array}{l}\mathbf{R} \\
\mathbf{E} \\
\mathbf{P} \\
\mathbf{R}\end{array}$ & \multicolumn{2}{|c|}{ REPRESENTAÇÕ̃ES CONCEITUAIS - foco no produto. } \\
\hline $\begin{array}{l}\mathbf{T} \\
\mathbf{A} \\
\mathbf{F} \\
\mathbf{U} \\
\mathbf{N} \\
\mathbf{C} \\
\mathrm{C} \\
\mathbf{0}\end{array}$ & $\begin{array}{l}\text { S } \\
\text { E } \\
\text { N } \\
\text { T } \\
\text { A } \\
\text { C } \\
\text { I } \\
0 \\
\text { N } \\
\text { A } \\
\text { D }\end{array}$ & \multicolumn{2}{|c|}{$\begin{array}{l}\text { REPRESENTAÇÃO DOS ATORES SOCIAIS } \\
\text { Caracterização cultural (as mulheres são representadas pelos sapatos vermelhos de salto } \\
\text { alto) apesar da exclusão física de qualquer pessoa no anúncio }\end{array}$} \\
\hline
\end{tabular}

Podemos depreender desta análise que os elementos da função composicional se apresentam de forma similar aos do anúncio 2: o produto é centralizado na página e as cores do pote são as predominantes no texto. Entretanto, percebemos aqui que o destaque ao produto se faz de forma mais sutil. Percebemos que não há dúvidas sobre a aparência do produto e a marca, que sempre devem estar evidenciados neste gênero. Para isso, o hidratante é destacado pela luz que forma uma moldura e a marca (L’oréal Men Expert) é vista em uma caixa laranja no canto inferior esquerdo (representando o que é novo e real, ou seja, desejável, mas fácil de alcançar).

O que mais chama a atenção no anúncio 2 é a estratégia de persuasão empregada: a criação de inimigos. Neste caso, usa-se a ideia (considerada como "verdade” em nossa sociedade) de que "homens não podem usar produtos de mulheres” e o produto é vendido como uma opção para aqueles que querem se cuidar com um hidratante feito especialmente para eles (os homens). Na imagem, as mulheres são trazidas para o texto 
pela figura dos sapatos vermelhos, o que se trata de uma caracterização cultural: somente mulheres usam tais sapatos (representação facilmente reconhecida onde vivemos). Assim, delimita-se o que é para homens (o creme anunciado) e o que pertence ao universo das mulheres (sapato de salto alto e outros hidratantes).

Um dos pontos que percebemos ao analisar a linguagem verbal no anúncio 2 quanto à Representação dos Atores Sociais é a construção de diferenciação entre “you” (você, homem/leitor) e ela (mulher), delimitando claramente dois grupos sociais: um dos homens e outro das mulheres. Elas não são nem por uma vez realmente classificadas no texto (como também não são vistas na foto), mas agrupadas por associação. O pronome possessivo "her”, usado duas vezes, representa esse grupo social, que se contrapõe à palavra "men”, que designa o grupo do qual o leitor (“you”) faz parte. A frase “Her skin doesn’t face daily shaving or the sensation of razor burn”, também marca o contraste entre esses dois grupos e abaliza a leitura "os homens enfrentam barbeação diária e sensação de ardência por causa da lâmina”, reforçando a desigualdade quanto ao que cada um precisa para se cuidar. Portanto, tanto a linguagem escrita como a visual menciona as mulheres indiretamente associando-as a algo que elas têm/usam e diferenciando-as dos homens sem citá-las/mostrá-las diretamente. Da mesma forma, o vocábulo “our” em “our moisturisers” é associado à empresa fabricante e ao mesmo tempo ocorre a diferenciação quanto aos hidratantes de outras empresas, o que está implícito no texto.

Além disso, a informação é passada de forma precisa e direta, buscando a praticidade normalmente ligada ao público masculino. Primeiramente, a propaganda tenta convencer o leitor através da contração dialógica por negação. Em "You wouldn’t wear these (so why use her moisturiser?)”, a leitura seria feita da seguinte forma: você não usaria estes sapatos, portanto, também não é certo utilizar cremes femininos. Assim, a defesa do hidratante anunciado é feita pela “lógica” e o produto é apresentado como a solução para um problema.

Os atributos do creme também se mostram de forma bem direta: “Complete care: 1 step, 5 actions”. Diferente das propagandas para as mulheres, os benefícios não são explicados em detalhes. Tudo o que se informa é que "basta usar" para ter resultados em 5 vertentes”, sem dizer quais são. O leitor é notificado apenas sobre a revitalização da pele, que é o foco do produto, e tem-se a promessa de um tratamento “completo", evidenciado em “complete care” e em “It’s not a facelift, it’s Vita Lift”. A gradação é 
um dos recursos presentes neste texto, pela repetição do mesmo item lexical (“L’oréal” - 2 vezes, “men” ou “man”- 4 vezes, Moisturizer - 4 vezes, Expert - 3 vezes).

\section{EXEMPLIFICAÇÃO DE ATIVIDADES}

Sabendo da necessidade do desenvolvimento de práticas que promovam a leitura crítica, não só de textos verbais, mas também das imagens, como aponta Sardelich (2006, p.466) em seu artigo sobre a cultura visual, proponho mostrar, alguns exemplos de como explorar criticamente textos multimodais na escola. A partir de todo o processo de análise e resultados, desenvolvi algumas atividades para a leitura do texto, que foram aplicadas em uma turma de ensino médio de Farmácia de Inglês básico em duas aulas de 1h30min cada. Antes dessas aulas, outros gêneros multimodais já haviam sido vistos e parte da teoria envolvida já tinha sido discutida com os alunos.

A elaboração das atividades se baseou principalmente na proposta de Ramos (2004), que oferece alternativas para desenvolver tarefas que, do ponto de vista pedagógico, levam em conta o aspecto de gradação e progressão de conteúdo, reconhecimento de componentes dos gêneros e apropriação do conhecimento para o uso prático dos alunos. A implementação da proposta é desenvolvida em três fases, a saber, apresentação, detalhamento e aplicação, que são devidamente exemplificadas. Atividades em pares e em grupos foram privilegiadas na construção das tarefas mostradas aqui visando promover a construção conjunta do conhecimento (Oliveira, 2006, Bambirra, 2007). A abordagem da multimodalidade nos exemplos que proponho se apoiou também no trabalho de Oliveira (2006), que mostra a viabilidade de propostas de letramento visual nas aulas de ESP (Inglês para Fins Específicos) e que tem como principal meta munir os alunos de ferramental teórico para se posicionar criticamente com relação às imagens. Apresento a seguir as figuras das folhas utilizadas em turmas de ensino médio, subdividas seguindo a proposta de Ramos (2004).

A apresentação, exemplificada na figura 3, visa à criação de condições para que os alunos tenham uma perspectiva ampla do gênero e mostrar o quanto eles já sabem sobre o mesmo. Assim, as atividades buscam fazê-los usar seu conhecimento prévio e de mundo e pensar sobre o contexto em que tal texto está inserido para promover a conscientização e familiarização. 
Figura 3 - Atividades de Apresentação.

I) Organizem-se em grupos de quatro pessoas. Cada grupo receberá uma revista. Observem-na e discutam as perguntas:

a. Que gêneros podemos encontrar nela?

b. Essa revista tem um público-alvo específico? Qual é ele?

c. Você se enquadraria no grupo de leitores deste tipo de revista? Por quê (não)?

d. Quais seções você gostaria de ler? Por quê?

e. Que tipos de produtos/serviços são anunciados nesta revista?

f. Você acha que existe alguma ligação entre o tipo de revista e o produto/serviço anunciado?

II) O que você sabe sobre anúncios publicitários? Discuta as questões de acordo com a sua experiência:

a. Quais são as funções dos anúncios impressos?

b. Você pode citar algum exemplo deste gênero? Qual é a função deste texto que você mencionou?

c. Que pessoas são envolvidas no processo de produção e veiculação desses textos?

d. Quais são algumas características desses anúncios? Faça uma lista com os colegas.

e. Por que as pessoas leem esses textos?

f. Quais são algumas estratégias utilizadas para convencer o leitor?

g. Com que propósitos as imagens são usadas em anúncios?

A fase de detalhamento consiste no exame do contexto cultural e situacional em que o texto se insere, o que é exemplificado nas atividades a seguir da figura 4.

Figura 4 -Atividades de Detalhamento.

III) Nós vamos ler um anúncio publicitário que foi publicado em uma página da revista Marie Claire de 2011. Para uma melhor visualização, o texto escrito está reproduzido ao lado e abaixo da página. Observe o texto da revista e responda:

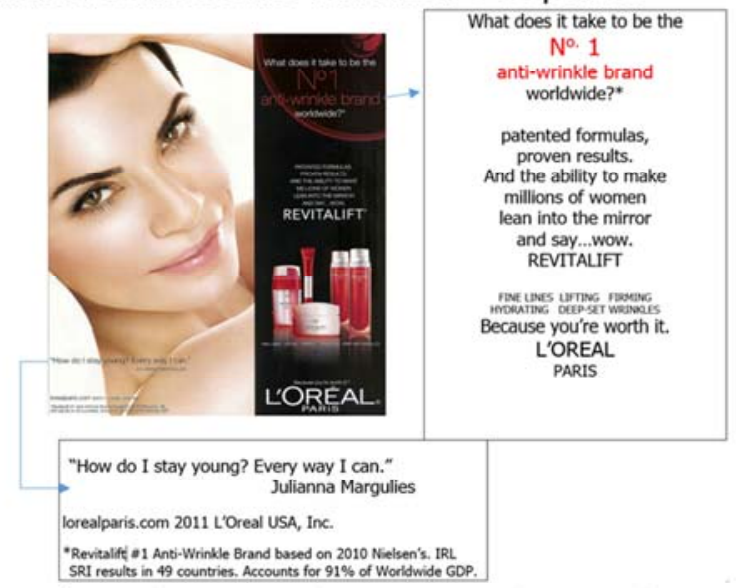

a. Qual produto está sendo anunciado? Como podemos saber?

b. Qual é o público-alvo desta propaganda?

c. Quais são seus propósitos comunicativos?

d. Qual é a marca do produto anunciado? Onde esta informação se encontra no texto?

IV) Reúnam-se em duplas. Vamos dividir o texto em quatro partes: superior, inferior, direita e esquerda. Observe $o$ anúncio e discuta as perguntas:

a) O que está mais para o centro da figura como um todo? Qual é o efeito dessa escolha? 
b) O que é mostrado na página esquerda? E na direita? Qual delas normalmente leríamos primeiro? A qual é dada maior importância?

c) Qual delas (a página direita ou a esquerda) apresenta:

- a informação nova (o que é desejado, a surpresa, a novidade)

- a informação dada (algo que o leitor já sabe, o que é familiar)

d) Que outras estratégias são utilizadas para fazer com que o produto se destaque?

v) Como a atriz é representada na imagem e por que essas escolhas foram feitas? Discuta:

a. Ela mantém contato ocular com o leitor? De que ângulo? (seu rosto está de frente para quem olha, como se houvesse envolvimento, ou ela virou a cabeça para o lado?)

b. Ela é mostrada como uma pessoa próxima ou distante do leitor? Como se conseguiu esse efeito?

c. Julianna parece estar acima, abaixo ou em posição de igualdade com quem a observa?

d. O que está acontecendo na imagem? (Que outros elementos aparecem ao lado ou atrás da atriz? O que ela está fazendo?) Ela é representada como agente?

VI) Agora, examinem a linguagem verbal e circulem no texto as palavras que vocês conhecem e as que vocês podem inferir pela semelhança com o Português. Responda as perguntas e comparem sua leitura com a dos colegas.

a. Que estratégias de persuasão são utilizadas? Que elementos são utilizados para elevar as qualidades do produto, dar força à marca, fazer o leitor memorizá-la mais facilmente e ter vontade de consumir?

b. Há palavras que são repetidas? Liste-as e informe ao lado quantas vezes elas aparecem.

\begin{tabular}{|c|c|}
\hline Exemplos & № de vezes \\
\hline & \\
\hline
\end{tabular}

c. Usam-se comparativos e/ou superlativos?

d. Há palavras que podem ser consideradas como de alta intensidade (como SEMPRE)?

e. $\mathrm{O}$ anúncio faz uso de números? Com que objetivo?

VII) As perguntas transcritas abaixo foram extraídas do texto. A quem cada uma delas é atribuída e por que elas são trazidas no anúncio?

a) "How do I stay young? Every way I can"?

b) "What does it take to be the No 1 anti-wrinkle brand worldwide?"

VIII) De que forma o que as interpretações das análises desenvolvidas nas atividades VI, e VII se relacionam ao que foi discutido quanto às escolhas na imagem? Há repetições das mensagens construídas pelo verbal e pelo visual? (Quais?)

No momento de aplicação, o aluno é exposto a outros exemplos (consolidação) e às suas situações de uso (apropriação), como pode ser visto na figura 5.

Figura 5 -Atividades de Aplicação

IX) Leiam os anúncios abaixo e analisem-nos em grupos. A parte escrita foi copiada ao lado para que seja lida mais facilmente. Depois, comparem seus comentários com os de outros grupos. Lembrem-se de mencionar:

a. O contexto em que o anúncio está inserido

b. Como o anúncio se organiza espacialmente, qual o valor das informações de acordo com o contexto, se há linhas ou setas na imagem e qual a sua função.

c. Como os atores sociais são representados (Eles estão "envolvidos em ação"? O que está acontecendo na imagem? Eles são agente na linguagem verbal?)

d. Se há repetições ou quantificações na linguagem escrita e/ou verbal e qual seu efeito na mensagem vinculada. 


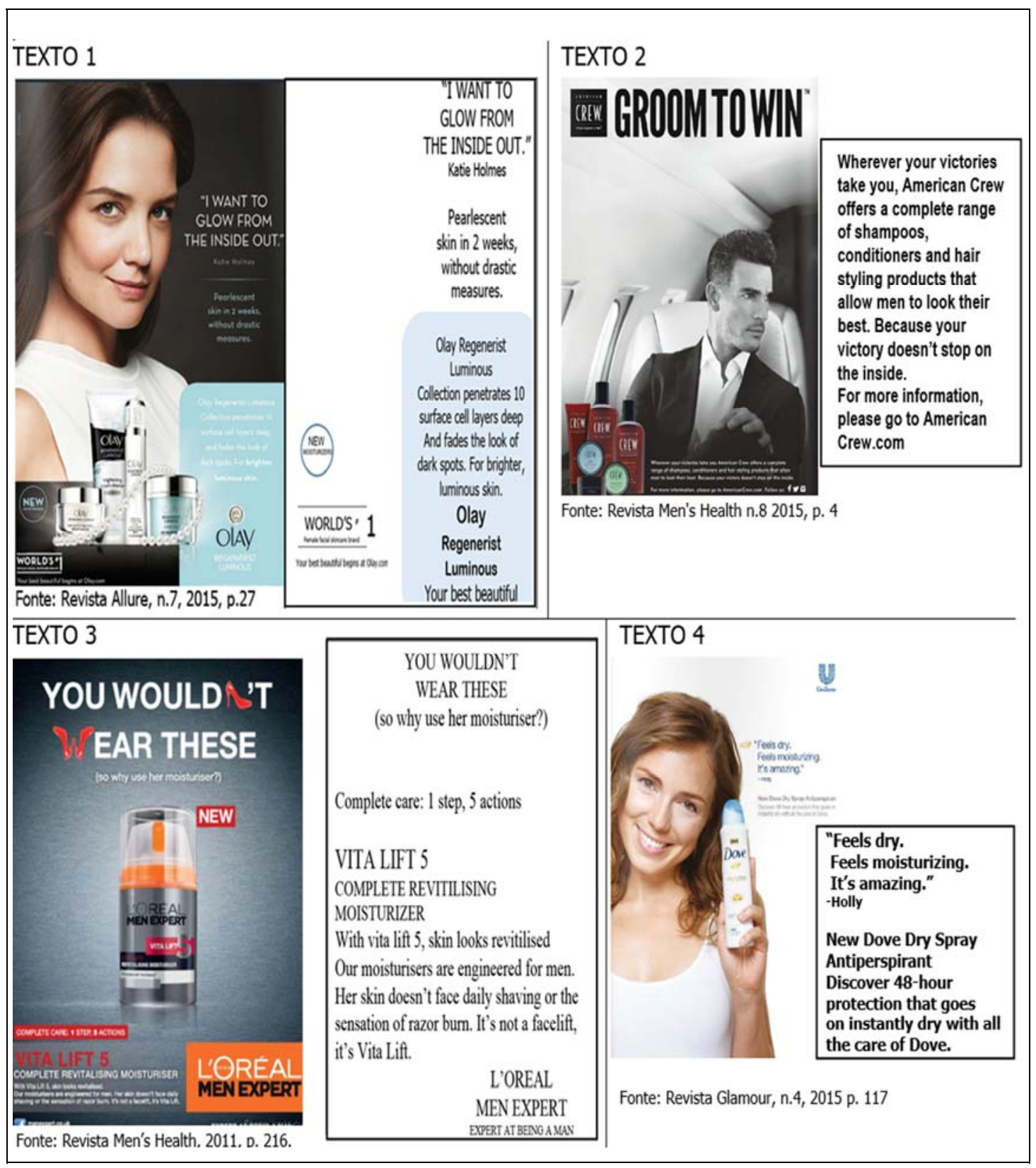

\section{CONSIDERAÇÕES FINAIS}

A necessidade do desenvolvimento de práticas que promovam a leitura crítica, não só de textos verbais, mas também das imagens, se evidência em nossas salas de aula. Este trabalho teve como principal objetivo apresentar uma proposta de leitura de textos multimodais utilizando o arcabouço teórico oferecido pela Linguística SistêmicoFuncional. Para tanto, foram utilizados anúncios publicitários, examinados pelas categorias para a representação dos atores sociais e pelas indicadas na Gramática do Design Visual. As mensagens veiculadas pelas linguagens visual e verbal foram comparadas e contrastadas e foram feitas algumas considerações sobre como elas são muito bem manipuladas para que se alcance o principal propósito comunicativo do 
gênero: persuadir o leitor a adquirir, utilizar ou se envolver com o que está sendo anunciado. Seguindo a análise, foram mostradas algumas atividades que são um exemplo de como o exame dos textos poderiam ser conduzidos em aulas de Inglês.

Os dois encontros com as turmas em que as atividades foram desenvolvidas contaram com grande participação e curiosidades dos alunos. Seu interesse os fez se engajar na leitura crítica de outros anúncios, como também de outros gêneros, que foram selecionados por eles e trazidos para discussão em outras aulas.

Diante das reflexões realizadas durante o processo de pesquisa, análise e posteriores sugestões de atividades, acredito que este trabalho representa um passo no sentido de estimular e dar subsídios para que os alunos leiam criticamente e para que outros professores se envolvam na investigação de meios de ensinar a questionar gêneros multimodais.

\section{REFERÊNCIAS}

ALMEIDA, D. B. L. Beyond the playground: the representation of reality in fashion dolls’ advertisements. Linguagem em (Dis)curso, v. 8, n. 2, p. 203-228, 2008.

BAMBIRRA, Maria Raquel. Uma abordagem via gêneros textuais para o ensino da habilidade de leitura no 'inglês instrumental'. The ESPecialist, v.28, $\mathrm{n}^{0}$ 2, p.137-157, 2007.

CITELLI, A. Linguagem e persuasão. São Paulo: Ática, 2004.

DEVITT, A. Teaching critical genre awareness. In: BAZERMAN, C., BONINI, A., FIGUEIREDO, D. Genre in a changing world, Indiana: Parlor press, 2009.

DUARTE, L. C. R. P. O gênero anúncio: uma análise multimodal e semiolinguística da construção argumentativa. Dissertação submetida ao Programa de Pós-Graduação em Linguística da Universidade Federal do Ceará. Fortaleza, 2011

KRESS, G.; VAN LEEUWEN, T. Reading Images: the grammar of graphic design. London: Routledge, 2006.

MARTIN, J. R. Genre and Institutions: Social Processes in the Workplace and School. London: Cassell, 1997.

NASCIMENTO, R. et al. Multiletramentos: iniciação à análise de imagens. Linguagem \& Ensino, v. 14, p. 529-552, 2011.

OLIVEIRA, S. Texto visual e leitura crítica: o dito, o omitido, o sugerido. Linguagem \& Ensino, v.9, n.1, p. 15-39, 2006. 
PEREZ, C. Signos da marca: expressividade e sensorialidade. São Paulo: Thomson Learning, 2004.

RAMOS, R. C. G. Gêneros textuais: uma proposta de aplicação em cursos de inglês para fins específicos. The ESPecialist, v. 25, n. 2, p. 107-129, 2004.

RESEnDE, V. M. \& RAMALHO, V. Análise de Discurso Crítica. São Paulo: Contexto, 2006.

SAMPAIO, Rafael. Propaganda de A a Z. Rio de Janeiro: Elsevier, 2003.

UNSWORTH, L. Teaching multiliteracies across the curriculum: changing contexts of text and image in classroom practice. Buckinghan / Philadelphia: Open University Press, 2001.

VAN LEEUWEN, T. A representação de actors sociais. In: PEDRO, E. (Org.). Análise Crítica do Discurso. Lisboa: Ed. Caminho, p. 169-222, 1997.

VAN LEEUWEN, T. Discourse and Practice - new tools for critical discourse analysis. New York: Oxford University Press, 2008.

\section{A AUTORA}

Carla Cristina de Souza é doutoranda em Estudos da Linguagem da Pontifícia Universidade Católica do Rio de Janeiro. Fez a graduação em Letras (Português/Inglês, Bacharelado e Licenciatura) pela UFRJ e concluiu a Especialização em Linguística Aplicada e Mestrado em Linguística na UERJ. Trabalhou como Professora Substituta de Didática Especial de Inglês/Prática de Ensino de Português-Inglês na UFRJ. Hoje é professora de Inglês no Instituto Federal do Rio de Janeiro (IFRJ). Suas áreas de interesse compreendem Análise Crítica do Discurso, Linguística Aplicada, Linguística Sistêmico-Funcional, Multiletramentos, Gêneros Discursivos e Formação de Professores.

E-mail: wscarla@hotmail.com 